\title{
Hypoadrenocorticism in a Kitten
}

\author{
Jenchieh Chuang, Yuting Hsiao and Jyhmirn Lai* \\ National Chiayi University, Department of Veterinary Medicine, No. 580, Xin Min Rd, Chiayi City, 600, Taiwan \\ ${ }^{\star}$ Corresponding author: Jyhmirn Lai, National Chiayi University, Department of Veterinary Medicine, No. 580, Xin Min Rd, Chiayi City, 600, Taiwan, R.O.C; Tel: \\ +886-5-2732920; Fax: +886-5-2732917; E-mail: Jyhmirn@mail.ncyu.edu.tw
}

Received: February 03, 2021; Accepted: February 13, 2021; Published: February 20, 2021

\begin{abstract}
This case describes how a 7-month-old, female, intact kitten was diagnosed with hypoadrenocorticism and fully recovered after treatment with fludrocortisone acetate. The cat showed signs of weight loss, severe weakness, and anorexia. Clinical findings included severe dehydration, lethargy, and moderate hypothermia. Blood examinations showed severe azotemia, hypernatremia, hypochloremia and hyperkalemia. Hypoadrenocorticism was diagnosed on the basis of low cortisol concentration during hospitalization. The cat had a full recovery after being treated with on daily dosage of fludrocortisone acetate and prednisolone; and is still well after one year. We believe this is the first case describing hypoadrenocorticism in a kitten younger than 12 months. This case demonstrates the success of fludrocortisone acetate as the treatment, using the level of cortisol concentration as an index; and that evaluating the cortisol concentration is a good method to monitor the change of hypoadrenocortism; and that hypoadrenocorticism could be reversed with a good treatment.
\end{abstract}

Keywords: Cortisol, Feline, Fludrocortisone acetate, Hypoadrenocorticism, Kitten

\section{Introduction}

Hypoadrenocorticism, also known as Addison's disease (AD), is a severe or total deficiency of cortisone. AD is well-described in dogs. Its estimated prevalence is $0.3 \%$ to $1.1 \%$ [1] and is generally diagnosed at the age between 3 months and 14 years [2,3]. Confirmation of the $\mathrm{AD}$ diagnosis is often by ACTH stimulating test and its reading of the cortisol levels in blood [2,4-6]. However, testing the basal plasma cortisol level could be an easier, more reliable and less costly method than ACTH stimulating test [7]. AD is rarely reported in cats. Up to date, approximate 40 cases have been reported [8-18]. In cats, primary $\mathrm{AD}$ is less likely to be found, even rarer in cats younger than 12 months. The majority of patients are shorthair domestic cats $[8,11,13]$; and the onset age is between 1.5 to 14 years old (median 5 years old) [13]. There is no clear evidence showed the morbidity with sex, age and breeding in cats [5]. Some case reports showed that a few factors, such as corticosteroid or/and megestrol acetate withdrawal, neoplastic infiltration, immune-mediated problem, and trauma could contribute to primary or secondary $\mathrm{AD}[8,14,15,19]$.'

Basically, an excellent outcome of $\mathrm{AD}$ can be achieved by using medicines, with a post-diagnosis life expectancy of up to 70 months [20]. There are two protocols to treat $\mathrm{AD}$, using either the combination of methyprednisolone and DOCP or the combination of fludrocortisone acetate and prednisone/prednisolone $[2,5,13]$. Reports stated a consecutive treatment by using the second protocol can keep the cats alive over than one year without clinical signs $[12,13,16,18]$. The case aims to describe an $\mathrm{AD}$ occurred in a very young kitten and the good outcome after diagnosis and treatment as, based on the authors' knowledge, no report has described $\mathrm{AD}$ in a kitten age under 1 year old.'

\section{Case Description}

A 7 months old, female intact, and mixed breed shorthair cat was referred to a small animal clinic with a body weight of $1.6 \mathrm{~kg}$ and a body condition score of 3/9. The owner said the kitten showed progressive lethargy, unwilling to move, intermittent vomiting and diarrhea 3 weeks ago. The cat had no record of using exogenous steroid or mestrol acetate. After performing the physical examination (Day 0 ), the patient also showed clinical signs of progressive weight loss, hypothermia $\left(36.5^{\circ} \mathrm{C}\right)$, anorexia, $10 \%-12 \%$ dehydration, and mucous membranes were pale and dry. Thoracic auscultation, abdomen palpation and neurological examination, blood pressure, heart rate, and respiratory rate were within normal range. The FIV/FeLV/FCoV (Speed Trio, Virbac) and the feline distemper kit (FPV Ag Test Kit, Bionote Anigen) displayed negative results.'

Serum biochemistry revealed electrolyte abnormalities, severe azotaemia, and dehydration (Tables 1 and 2). Urinalysis showed isosthenuria (specific gravity 1.011), and mild proteinuria (1+). Abdominal radiography and ultrasonography returned no specific finding. Based on above findings, taking account of especially the values of electrolytes, this case could be either acute kidney injury (AKI) or AD.'

On Day 0, the initial treatments included intravenous (IV) fluid therapy. The cat received $100 \mathrm{~mL}$ of $0.9 \%$ normal saline subcutaneously and $0.9 \%$ normal saline was administered at $120 \mathrm{~mL} / \mathrm{kg} /$ day to correct the dehydration. Two $\mathrm{mL}$ of $10 \%$ calcium-gluconate IV and 1 IU of regular insulin SC were administered as a cardioprotective agents because of the severe hyperkalemia. To avoid hypoglycemia, $1 \mathrm{~mL}$ of $10 \%$ glucose was injected by IV slowly. $200 \mathrm{mg}$ lanthanum carbonate was given twice daily PO for hyperphosphatemia. Eight hours later, the 
Table 1: Serial monitoring of hematological parameters in the kitten.

\begin{tabular}{|c|c|c|c|c|c|c|c|c|}
\hline Parameter & unit & Day 0 & Day 2 & Day 8 & Day15 & Day21 & Day 213 & RI \\
\hline $\mathrm{RBC}$ & $\mathrm{M} / \mu \mathrm{L}$ & 9.98 & 7.26 & 7.82 & 5.58 & 5.68 & & $6.54-12.20$ \\
\hline HCT & $\%$ & 36.1 & 27.0 & 29.2 & 21.0 & 23.5 & 25.6 & $30.3-52.3$ \\
\hline HGB & $\mathrm{g} / \mathrm{dL}$ & 13.3 & 11.4 & 10.3 & 7.6 & 7.7 & 8.8 & $9.8-16.2$ \\
\hline MCV & $\mathrm{fL}$ & 36.2 & 37.2 & 37.3 & 37.6 & 41.4 & 41.0 & $35.9-53.1$ \\
\hline $\mathrm{MCH}$ & $\mathrm{pg}$ & 13.3 & 15.7 & 13.2 & 13.6 & 13.6 & 14.1 & $11.8-17.3$ \\
\hline $\mathrm{MCHC}$ & $\mathrm{g} / \mathrm{dL}$ & 36.8 & 42.2 & 35.3 & 36.2 & 32.8 & 34.4 & $28.1-35.8$ \\
\hline RDW & $\%$ & 29.0 & 24.9 & 29.9 & 25.5 & 33.8 & 22.4 & $15.0-27.0$ \\
\hline RETIC & $\mathrm{K} / \mu \mathrm{L}$ & 3.0 & 2.9 & 25.8 & 4.5 & 67.6 & 5.6 & \\
\hline RETIC-HGB & pg & & & 15.7 & 14.8 & & & $3.0-50.0$ \\
\hline WBC & $\mathrm{K} / \mu \mathrm{L}$ & 12.02 & 17.01 & 11.70 & 11.20 & 8.46 & 10.48 & $2.87-17.02$ \\
\hline NEU & $\mathrm{K} / \mu \mathrm{L}$ & 9.65 & 12.49 & 10.16 & 7.38 & 4.92 & 5.34 & $1.48-10.29$ \\
\hline LYM & $\mathrm{K} / \mu \mathrm{L}$ & 1.98 & 3.38 & 0.92 & 3.03 & 2.26 & 3.14 & $0.92-6.88$ \\
\hline MONO & $\mathrm{K} / \mu \mathrm{L}$ & 0.31 & 0.29 & 0.54 & 0.33 & 0.70 & 0.25 & $0.05-0.57$ \\
\hline EOS & $\mathrm{K} / \mu \mathrm{L}$ & 0.01 & 0.27 & 0.00 & 0.35 & 0.44 & 1.67 & $0.17-1.57$ \\
\hline BASO & $\mathrm{K} / \mu \mathrm{L}$ & 0.07 & 0.58 & 0.08 & 0.11 & 0.14 & 0.08 & $0.01-0.26$ \\
\hline PLT & $\mathrm{K} / \mu \mathrm{L}$ & 574 & 272 & 813 & 285 & 994 & 275 & $151-600$ \\
\hline MPV & $\mathrm{fL}$ & 18.2 & 17.8 & 16.7 & 16.9 & 16.2 & 17.6 & $11.4-21.6$ \\
\hline
\end{tabular}

RBC: Red Blood Cell; HCT: Haematocrit; HGB: Hemoglobin; MCV: Mean Cell Volume; MCH: Mean Cell Hemoglobin; MCHC: Mean Corpuscular Hemoglobin Concentration; RDW: Red Cell Distribution Width; RETIC: Reticulocyte; RETIC-HGB: Reticulocyte Hemoglobin; WBC: White Blood Cell; NEU: Neutrophil; LYM: Lymphocyte; MONO: Monocyte; EOS: Eosinophil; BASO: Basophil; PLT: Platelet; MPV: Mean Platelet Volume.

Table 2: Serial monitoring of the serum biochemistry in the kitten.

\begin{tabular}{|c|c|c|c|c|c|c|c|c|c|c|c|c|c|c|c|c|c|}
\hline parameter & Unit & initial & $8 \mathrm{~h}$ & Day 1 & Day 2 & Day 3 & Day 10 & Day 13 & Day 17 & Day 21 & Day 22 & Day 23 & Day 24 & Day 25 & Day 26 & Day 213 & RI \\
\hline Glucose & $\mathrm{mg} / \mathrm{dL}$ & 227 & 44 & 141 & 156 & & 161 & & 148 & & & & & & & 116 & 74-159 \\
\hline Total protein & $\mathrm{g} / \mathrm{dL}$ & 10.3 & & & 8.1 & & 10.2 & & 7.2 & 7.9 & 7.2 & 7.5 & 6.7 & 7.5 & & 7.2 & $5.7-8.9$ \\
\hline Albumin & $\mathrm{g} / \mathrm{dL}$ & 4.1 & & & 3.8 & & 4.5 & & 3.4 & & & & & & & 3.2 & $2.2-4.0$ \\
\hline BUN & $\mathrm{mg} / \mathrm{dL}$ & $>130$ & & 62 & 40 & & 110 & 42 & 37 & 42 & 30 & 28 & 26 & 31 & & 41 & $16-36$ \\
\hline Creatinine & $\mathrm{mg} / \mathrm{dL}$ & Over & & 1.9 & 1.7 & & Over & 1.5 & 1.5 & 2.5 & 1.9 & 1.9 & 2.2 & 1.9 & & 3.3 & $0.8-2.4$ \\
\hline ALT & $\mathrm{U} / \mathrm{L}$ & 13 & & & 80 & & 22 & & 25 & & & & & & & & $12-130$ \\
\hline ALP & $\mathrm{U} / \mathrm{L}$ & & & & 17 & & 25 & & 18 & & & & & & & & $14-111$ \\
\hline Inorganic phosphorus & $\mathrm{mg} / \mathrm{dL}$ & 14.0 & & 6.3 & 5.4 & & $>16.1$ & 6.0 & 5.4 & & & & & 6.8 & & & $3.1-7.5$ \\
\hline Calcium & $\mathrm{mg} / \mathrm{dL}$ & 10.9 & & & & & & & 10.0 & & & & & & & & $7.8-11.3$ \\
\hline Potassium & $\mathrm{mmol} / \mathrm{L}$ & 8.1 & 4.7 & 7.1 & 4.4 & 4.3 & 7.5 & 4.3 & 3.5 & 4.4 & 4.1 & 4.4 & 4.1 & 4.0 & 5.3 & 4.7 & $3.5-5.8$ \\
\hline Sodium & $\mathrm{mmol} / \mathrm{L}$ & 133 & 140 & 143 & 148 & 146 & 132 & 160 & 160 & 153 & 154 & 156 & 154 & 155 & 162 & 158 & $150-165$ \\
\hline Sodium/potassium & & 16 & 30 & 20 & 34 & 34 & 18 & 37 & 45 & 35 & 38 & 35 & 37 & 39 & 31 & 34 & \\
\hline Chlorine & $\mathrm{mmol} / \mathrm{L}$ & 98 & 106 & 108 & 109 & 111 & 100 & 123 & 120 & 117 & 117 & 119 & 119 & 116 & 118 & 127 & $112-129$ \\
\hline
\end{tabular}

BUN: Blood Urea Nitrogen; ALT: Alanine Aminotransferase; ALKP: Alkaline Phosphatase.

potassium concentration had become normal. After another injection of $1 \mathrm{~mL}$ of $10 \%$ glucose, the patient's appetite, spirit started to improve at midnight, and its body temperature gradually returned to $38.4^{\circ} \mathrm{C}$. On Day 1, the potassium concentration increased again. The order was the same as Day 0. On Day 2, the potassium and Inorganic phosphate returned to the normal range so cardioprotective agents and lanthanum carbonate were stopped. The kitten presented polyuria/polydipsia. The haematological results showed mild anemia. The BUN was slightly higher and the electrolytes (sodium and chloride) were slightly lower. The other biochemical values were normal. At this point, the kitten had been rescued from emergency situation.'

Consequently, IV fluid was changed to $60 \mathrm{~mL}$ of $0.9 \%$ saline subcutaneous once daily, On Day 3, the owner asked the kitten to be discharged. We prescribed the same treatment as Day 2. One week later, on Day 10, the patient's condition worsened again and was rehospitalized. It showed anorexia, lethargy, and severe dehydration. Based on the previous data, we considered the possibility of a rare disease, Addisonian crisis. Haematological and biochemical findings showed mild non-regenerative anemia, severe azotemia, and electrolytes abnormal (Tables 1 and 2). The cat was administered $0.9 \%$ normal saline at $120 \mathrm{~mL} / \mathrm{kg} /$ day and dosed $0.02 \mathrm{mg} / \mathrm{kg}$ fludrocortisone acetate and $0.5 \mathrm{mg} / \mathrm{kg}$ prednisolone oral once daily as mineralocorticoid and glucocorticoid supplements. On Day 15, the value of cortisol concentration $(1.1 \mathrm{ug} / \mathrm{dL})$ became lower than the reference value. On Day 26, the value of cortisol concentration came up to the normal range $(2.7 \mathrm{ug} / \mathrm{dL})$ so we decided to tapered and then stopped the oral drugs. On Day 332, the patient was spayed and its cortisol concentration was normal ( $2.7 \mathrm{ug} / \mathrm{dL})$ (Table 3$)$. The cat has been very well since its discharged a year ago.' 
Table 3: Serial monitoring of the serum cortisol concentration.

\begin{tabular}{|l|c|c|c|c|c|}
\hline parameter & unit & Day 15 & Day 26 & Day 332 & RI \\
\hline cortisol & $\mu \mathrm{g} / \mathrm{dL}$ & 1.1 & 2.7 & 2.7 & $1.7-4.2$ \\
\hline
\end{tabular}

\section{Discussion}

We believe this is the first report case of $\mathrm{AD}$ in an intact kitten younger than 1 years old. A report stated that the disease all occurred in neutered adults cats over than 1 years old and the mean age was $5.8 \pm 3.7$ and the range was between 1.5 and 14 [13]. Some researchers have stated that this disease can occur in 1 years old, neutered cats [10], in 3-6 years old cats $[12,16,18]$ and in cats older than 8 years old $[14,15,21,22]$. Our study advances the knowledge that AD can occur in an intact kitten younger than 1 year old.'

Whether to stop fludrocortisone acetate after the clinical signs have disappeared has been a controversial issue. Some researchers believe treatment of $\mathrm{AD}$ is lifelong because it cannot be reversed $[2,12,16,18,23]$. A report mentioned that a cat suffered from $\mathrm{AD}$ again after the treatment was changed from twice daily to once daily [12]. In fact, the decision of prescribing a consecutive treatment is based on how good the clinical signs and electrolyte are $[2,18,23]$. One case pointed out the cortisol concentration became to normal 40 days after the $\mathrm{AD}$ treatment by using prednisolone was stopped [21]. We believe to use fludrocortisone acetate could achieve the same result as the last case based on the change of the basal cortisol concentration in our case during the treatment. After Day 26, the cortisol concentration and other biochemical values have been normal. Treatment on the kitten stopped after Day 26. On Day 332, the cortisol concentration was still normal, indicating that the kitten had recovered from Addisonian crisis. The mechanism behind the kitten's recovery from $\mathrm{AD}$ is unknown.

In conclusion, this is the first case which describes $\mathrm{AD}$ in a kitten younger than 12 months old. Secondly, the case shows that evaluating the values of cortisol concentration is a good method to monitor the change of AD. Thirdly, fludrocortisone acetate is also a good method to treat $\mathrm{AD}$. And finally, AD could be reversed after a good treatment.'

\section{Acknowledgement}

We thank Dr. Pingchih Teng for his kindly suggestions during we wrote this report.

\section{References}

1. Bellumori TP, Famula TR, Bannasch DL, Belanger JM, Oberbauer AM (2013) Prevalence of inherited disorders among mixed-breed and purebred dogs: 27,254 cases (1995-2010). Journal of the American Veterinary Medical Association 242: 15491555. [crossref]

2. Greco DS (2007) Hypoadrenocorticism in small animals. Clinical Techniques in Small Animal Practice 22: 32-35. [crossref]
3. Peterson ME, Kintzer PP, Kass PH (1996) Pretreatment clinical and laboratory findings in dogs with hypoadrenocorticism: 225 cases (1979-1993). Journal-American Veterinary Medical Association 208: 85-91. [crossref]

4. Boag AM, Catchpole B (2014) A review of the genetics of hypoadrenocorticism. Topics in Companion Animal Medicine 29: 96-101. [crossref]

5. Duesberg C, Peterson ME (1997) Adrenal disorders in cats. Veterinary Clinics of North America: Small Animal Practice 27: 321-347. [crossref]

6. Van Lanen K, Sande A (2014) Canine hypoadrenocorticism: pathogenesis, diagnosis, and treatment. Topics in Companion Animal Medicine 29: 88-95. [crossref]

7. Lennon EM, Boyle TE, Hutchins RG, Friedenthal A, Correa MT et al. (2007) Use of basal serum or plasma cortisol concentrations to rule out a diagnosis of hypoadrenocorticism in dogs: 123 cases (2000-2005). Journal of the American Veterinary Medical Association 231: 413-416. [crossref]

8. Berger SL, Reed JR (1993) Traumatically induced hypoadrenocorticism in a cat. Journal of the American Animal Hospital Association 29: 337-339.

9. Brain PH (1997) Trauma-induced hypoadrenocorticism in a cat. Australian Veterinary Practitioner 27: 178-181.

10. Hock CE (2011) Atypical hypoadrenocorticism in a Birman cat. The Canadian Veterinary Journal 52: 893-896. [crossref]

11. Johnessee JS, Peterson ME, Gilbertson SR (1983) Primary hypoadrenocorticism in a cat. Journal of the American Veterinary Medical Association 183: 881-882.

12. Kasabalis D, Bodina E, Saridomichelakis MN (2012) Severe hypoglycaemia in a cat with primary hypoadrenocorticism. Journal of Feline Medicine and Surgery 14: 755758. [crossref]

13. Peterson ME, Greco DS, Orth DN (1989) Primary hypoadrenocorticism in ten cats. Journal of Veterinary Internal Medicine 3: 55-58. [crossref]

14. Romine JF, Kozicki AR, Elie MS (2016) Primary adrenal lymphoma causing hypoaldosteronism in a cat. Journal of Feline Medicine and Surgery Open Reports 2: 2055116916684409. [crossref]

15. Rudinsky AJ, Clark ES, Russell DS, Gilor C (2015) Adrenal insufficiency secondary to lymphocytic panhypophysitis in a cat. Australian veterinary journal 93: 327-331. [crossref]

16. Sicken J, Neiger R (2013) Addisonian crisis and severe acidosis in a cat: a case of feline hypoadrenocorticism. Journal of Feline Medicine and Surgery 15: 941-944. [crossref]

17. Tasker S, MacKay AD, Sparkes AH (1999) A case of feline primary hypoadrenocorticism. Journal of Feline Medicine and Surgery 1: 257-260. [crossref]

18. Woolcock AD, Ward C (2015) Successful treatment of a cat with primary hypoadrenocorticism and severe hyponatremia with desoxycorticosterone pivalate (DOCP). The Canadian Veterinary Journal 56: 1158-1160. [crossref]

19. Chastain CB, Graham CL, Nichols CE (1981) Adrenocortical suppression in cats given megestrol acetate. American Journal of Veterinary Research 42: 2029-2035. [crossref]

20. Myers N C, Bruyette DS (1994) Feline adrenocortical diseases: II Hypoadrenocorticism. In Seminars in Veterinary Medicine and Surgery (Small Animal) 9:144-147. [crossref]

21. Smith SA, Freeman LC, Bagladi-Swanson M (2002) Hypercalcemia due to iatrogenic secondary hypoadrenocorticism and diabetes mellitus in a cat. Journal of the American Animal Hospital Association 38: 41-44. [crossref]

22. Stonehewer J, Tasker S (2001) Hypoadrenocorticism in a cat. Journal of Small Animal Practice 42: 186-190. [crossref]

23. Meeking S (2007) Treatment of acute adrenal insufficiency. Clinical Techniques in Small Animal Practice 22: 36-39. 